MedieKultur | Journal of media and communication research | ISSN 1901-9726

Article - Theme section

\title{
Online deliberation and beyond? \\ A time-based and comparative study \\ of Danish political debates online
}

\section{Jakob Linaa Jensen}

MedieKultur 2014, 56, 23-43

Published by SMID | Society of Media researchers In Denmark | www.smid.dk The online version of this text can be found open access at www.mediekultur.dk

This article discusses online political debates in Denmark over a time period from 2001 to 2011 and compares three different online debates in 2011. By taking a timebased as well as a comparative perspective, it examines whether online debates have come closer to deliberative ideals of democracy and how online debates differ in form and content. The article particularly addresses the interplay between everyday and political discussions. It is demonstrated that shifts between the two forms of discussion often happen abruptly and that even people who tend not to become involved politically in a formal sense happily discuss politics in more informal, non-political settings. Furthermore, the article expands our understanding of demographic differences in political participation in debates online. All this helps enhance and broaden our concept of democracy in an online setting.

\section{Introduction}

The perspectives for democracy online have been debated since the mid-Nineties (Ess, 1996; Barber, 1998). It has been claimed that the Internet facilitates unhindered debate, fulfilling deliberative ideals of political discussion. Benjamin Barber (1998) has claimed that the Internet is a "new public sphere" replacing or, at least, substituting for traditional channels of political involvement: mediated channels such as newspapers, TV and radio and face-to-face channels like political rallies and town hall meetings. 
Discussions of the democratic potential of the Internet have coincided with a turn in democratic theory. Since the early 1980s, there has been a renewed focus on political participation and the necessity of democratic debate rather than mere institutionalized procedures. Joseph Bessette (1980) has used the term "deliberative democracy" to describe such a democratic ideal.

Many investigations of democratic phenomena online have taken their theoretical point of departure in ideas of deliberative democracy. The conclusions have been mixed. Davis (1999) in one of the first studies of online debates (in American election campaigns) demonstrated that the debates tended to be among like-minded people and that no real deliberation took place. Instead, the participants tended to have their existing beliefs confirmed through engagement with fellow Democrats or Republicans.

By contrast, through two American panel experiments in 2000 and 2004-2005, Vincent Price (2009) showed that, generally speaking, citizens fulfilled Habermasian ideals: they produced reasonably coherent political discussions, showed a willingness to debate and engage their opponents, developed opinions and grasped arguments for and against those views.

A number of studies have demonstrated that, although some online debates fulfill such criteria, the audience is limited to the "chosen few", those who are already politically engaged. Lincoln Dahlberg (2001) has investigated Minnesota E-Democracy, the longestlasting and most successful e-democracy project, dating back to 1994, which is still very active. He concludes that the debate in general is characterized by dialogue and mutual respect. However, the participation followed patterns from offline political participation in that the debate was dominated by the well-educated and already politically active. The same conclusion was reached by Linaa Jensen (2006), who studied Minnesota E-Democracy and similar regional debates in Denmark.

In a meta-study of online deliberation experiments, Albrecht (2006) establishes a model showing that traditional factors determining political participation such as education and income remain important for a willingness to engage online. Furthermore, he demonstrates that cultural factors such as experience and readiness to use ICTs pose a new barrier to engagement when it takes place online.

Since the experiences of online deliberation have been mixed, it still remains an open question whether the Internet can ultimately fulfill deliberative ideals of democracy. With respect to the potential of the Internet, Wright (2012) has argued that the schism between extreme optimistic or pessimistic expectations - what he calls ideas of revolution and normalization - has negatively influenced subsequent empirical analyses of political conversation online (and of e-democracy studies more generally).

For instance, many people are politically interested and willing to discuss politics and community issues but might be wary of debates strictly dedicated to politics. Rather than actively seeking political discussions, they are engaging due to "accidental political mobilization" (Hamilton \& Tolbert, 2012). Some online fora discussions turn political even though 
they are primarily intended for something else. They are not democratic or political according to strict ideals of deliberative democracy; nevertheless, they are politically relevant and democratically interesting. In other words, the truly deliberative potential of the Internet is underestimated if the theoretical focus is limited only to the level of deliberation or the empirical focus is limited strictly to political discussion groups.

\section{The study: the cases and the hypotheses}

Utilizing this idea, I will argue that it might be fruitful to take a comparative approach by looking at the development over time and analyzing various types of debates. In the following, I will pursue both tasks through time-based and comparative studies of Danish online political debates.

I will first compare the debates on the Danish usenet group dk.politik in 2001 and 2011. One might expect that, over a 10-year span, the debates might have come closer to deliberative ideals since the new medium has matured and participants have become more accustomed to online participation.

Second, I will compare dk.politik in 2011 with two very different online debate groups, Cafe Euroinvestor and Trendsales, in order to investigate the differences. Extending the focus to groups not originally intended for political debate can broaden the focus beyond narrow deliberative ideals of democracy. For instance, it might be expected that some citizens are politically interested and want to be involved and discuss things, provided that the discussions are not formally bound by existing discourses on the ideal character of political debates. The willingness to become involved politically might be demonstrated when citizens engaged in discussions of other topics suddenly turn in the direction of a political discourse, an example of accidental mobilization. Thus, the comparison of the three debates might reveal phenomena of political and democratic relevance that do not necessarily fulfill strict deliberative criteria.

Furthermore, the cases are also selected based on initial expectations of the gender composition of the participants. According to Herring (1996) and Butler (1999), for instance, men and women tend to discuss things differently. In general, females are more open-minded, open to negotiation and inclusive, whereas males are more conflict-oriented and often tend to radicalize their viewpoints in a debate. Cafe Euroinvestor was expected to be heavily male-dominated and Trendsales to be dominated by women. Dk.politik was expected to be more in-between although studies have demonstrated that usenet groups are often male-dominated (see, for instance, Linaa Jensen, 2003). By adding the gender aspect, an additional dimension is added to the explanation of possible differences between the cases.

Before presenting the cases in more detail and moving on to analysis, I will outline some key aspects of deliberative democracy that have formed the point of departure in this study. 


\section{Aspects of deliberative democracy}

Although deliberative democracy has come into fashion the last three decades, the ideas behind the concept are much older. Claims that dialogue is a prerequisite for a true democratic process can be traced back to ancient Greece (Elster, 1998: 1-2) and, later, the same idea has been proposed by conservative thinkers such as Edmund Burke and liberal thinkers such as John Stuart Mill. Danish Hal Koch (1991: 16) has stated that dialogue is the essence of democracy.

A fundamental reason deliberative democracy has become popular -particularly, in the Anglo-American academic tradition - is the translation into English in 1989 of Jürgen Habermas' work from 1962 on the structural transformation of the public sphere (Habermas, 1989). Although the work was 27 years old at that time, it spurred a renewed interest in ideas about the public sphere and the conditions for democratic dialogue. In the book, Habermas explores a historical phenomenon: the early democratic debates in English, French and German coffee houses in the $18^{\text {th }}$ century. For Habermas, this was the birthplace of modern democracy, further facilitated by the burgeoning number of newspapers of that time.

A central concept in Habermas' work is "discourse ethics", the procedures necessary for democratic debate (Habermas, 1975, 1996a, 1996b). Debate needs to be open to everybody; one has to listen to all arguments and to consider the public good rather than one's own interests. Habermas emphasizes that the conditions for debate in the coffee houses were close to such ideals. The deliberations took place without the struggles of particular interests, which tend to dominate modern institutionalized democracies.

Joseph Bessette (1994: 49) is more specific and lists three decisive elements in a deliberative process: argumentation, information and reciprocity. Argumentation is a central concept, but a debate also needs to take place based on enlightenment and the highest possible level of relevant information. Gutmann \& Thompson (1996) stress the importance of reciprocity, taking the ideas and interests of others into consideration. That idea resembles Immanuel Kant's categorical imperative; but, according to Gutmann \& Thompson (2003: 33), it ought to be fundamental in all theories of democracy.

Needless to say, such ideals have not remained uncontested. First and foremost, deliberative theorists have been criticized for unrealistic conditions and overly optimistic expectations on behalf of citizens. Cass Sunstein (2003) has pointed out that debates often cause increased polarization and radicalization rather than agreement and harmony. Others have highlighted the trade-off between deliberation and inclusion. Only a few people (among them, the best educated) may be able to live up to the strict criteria of discourse ethics, thus excluding those less educated and used to discuss. 


\section{The cases: dk.politik, Cafe Euroinvestor and Trendsales}

The first case, dk.politik, is a long-lasting discussion group originating from the so-called Usenet, which in 2001 became part of Google Groups (http://en.wikipedia.org/wiki/ Google_Groups). Dk.politik is used as a case, first, because it is still a major Danish political discussion group and, second, to compare it with a similar study from 2001. It is interesting to see whether the debate changed from 2001 to 2011, a period during which the Internet became a fully integrated part of most Danes' daily lives. Therefore, one might expect a more mature and dedicated use of the Internet than in 2001.

The second case is Cafe Euroinvestor, an online discussion forum within a broader commercial website, Euroinvestor.dk, which is dedicated to information and news updates for investors. Euroinvestor was founded in Denmark in 1997 but has spread its services to several other countries. The website Euroinvestor.dk is among the 25 most-visited websites in Denmark. Euroinvestor naturally hosts eager debates about stocks, bonds and markets. It also has a broader debate forum, Cafe Euroinvestor, for more general discussions. This analysis focuses on Cafe Euroinvestor, where the debates often address political topics.

The third case is a debate forum hosted by Trendsales.dk, a website dedicated to buying and selling second-hand clothing and other goods primarily from fashionable brands. It is among the largest second-hand websites in Denmark and has 300,000 monthly users (http://da.wikipedia.org/wiki/Trendsales).

Cafe Euroinvestor and Trendsales are included as cases in order to establish a mostdifferent case scenario for studying web debates (Yin, 2003). Unlike dk.politik, they are not specifically dedicated to the discussion of political topics. However, politics are discussed now and then in the more general debate forums. These discussions and, especially, the shifts between political and non-political discussions are the focus of this analysis.

It should be noted that there were several other candidates for inclusion in the analysis. Among the largest Danish websites hosting debate is Netbaby.dk, an Internet forum for parents and prospective parents. However, the debate forum was structured in a way that made it impossible to extract and process data. Another candidate was Hestenettet. $\mathrm{dk}$, which is the dominant forum for Danish horse owners. Although there are only a few thousand users, they are very dedicated, and the debates are lively. Netdoktor.dk is the largest portal for health-related issues in Denmark and also hosts a lively debate forum. It was, therefore, a candidate. In both these cases, it proved impossible to find enough debate dedicated to politics to justify the selection.

\section{Methods}

The debates are analyzed by applying computer-aided quantitative content analysis. Quantitative content analysis can be defined as a method for reducing the complexity of vast bodies of qualitative data (most often, text) and making it useful for quantitative analyses such as statistics (Krippendorf, 2012). There are two main approaches of coding. Auto- 
mated procedures include word-count, keyword-in-context (KWIC) and dictionary-based approaches (Weber, 1990). Where such methods are suitable for obtaining an overview of huge bodies of text, they are less adequate for extracting semantic meaning. So far, no computer programs can match the semantic intelligence of a human being. In this case, I want to evaluate the democratic quality of online debate. Deliberation and democracy in general are both essentially contested concepts (Connolly, 1983) that include many different aspects. Therefore, a human coding procedure was chosen for the three debates analyzed.

The first step in the procedure of quantitative content analysis is sampling. The original analysis of dk.politik took place in the months of April and May 2001. The debates comprised 2,308 and 4,217 posts, respectively. The posts were in various debate threads, ranging from one post to more than hundred, depending on the liveliness of the debates. A random sample of 10 percent of the debate threads was drawn from all the posts. Furthermore, for threads with more than 20 posts, only the first 20 threads were included in the sample in order to avoid certain threads taking up too much space in the sample. The resulting sample consisted of 311 posts.

For the debates in 2011, the approach was deeper as well as wider. On one hand, it was decided to limit the analysis to the month of April (which, as in 2001, was an average month with respect to the number of posts and participants). On the other hand, all the posts from the debates were included. Again, the "maximum 20 posts per thread" rule was applied. Furthermore, several threads were split and included posts from March and May. These were only included if they contained more than 5 posts from April, and only the posts from April were included. The sample on which the following analysis is based is illustrated in table 1.

\begin{tabular}{l|r|r|} 
& 2001 & 2011 \\
\hline Dk.politik & 311 & 1465 \\
Cafe Euroinvestor & - & 716 \\
Trendsales & - & 675 \\
\hline
\end{tabular}

Table 1: Sample sizes for the three debates. N.

It is noted that, although the number of posts on dk.politik is smaller in 2011 than in 2001, more posts are included in the analysis. Furthermore, the number of posts from dk.politik is about twice as big as from the two other debates, reflecting that it is still livelier than the other debates.

The debates were coded by two research assistants using the software MaxQda, which is state-of-the-art software for quantitative content analysis. Measures were taken to ensure a satisfactory validity and coder inter-reliability. The inter-coder test demonstrated a value of 0.90 . 
The overall aim of the analysis is to measure democratic quality operationalized by aspects of deliberation discussed above. I will argue that deliberation is both a matter of context (who is talking to whom and how), procedures (the level of reciprocity, argumentation and information) and content (whether the post is topically political, what the exact topic is, etc.). Therefore, a number of coding categories were developed for each of these three aspects. They are briefly described below.

There are three context categories: gender, anonymity versus openness and the tone of the post.

Gender (man or woman). Gender is included because it is expected, as mentioned, that men and women might have different debating styles.

Openness (Open, partially open, anonymous). This category denotes the revealed identity of the participant. It is expected that those identifying themselves might be more respectful than those remaining anonymous. "Open" means that a participant reveals his or her full name and e-mail address; "partially open" means that only one of the two is revealed; and "anonymous" means that it is impossible to identify the participant by either name or e-mail address.

Tone $(+2,+1,0,-1,-2)$. A prerequisite of democratic deliberation is mutual recognition and a respectful tone during the debates. Here, the tone of the participants is coded based on an interval scale in which a positive value denotes a positive, friendly tone in the posting and how other participants are treated and described. A negative value denotes the opposite. Positive values are ascribed, for instance, to mutual support or friendliness, whereas negative values are coded where messages contain hate speech or insults. In some posts, the tone shifts, and several values are applied throughout the message. Here, the final value is based on an average tone in the message.

There are two procedural categories: reciprocity and argumentation.

Argumentation $(+2,+1,0,-1,-2)$. Another fundamental prerequisite of deliberative ideals is argumentation. This category measures whether the participants make a valid argument (validated by external information or coherent argumentation) or, rather, merely make statements. Again, the codes are graduated along an interval scale in which a positive value denotes a high level of argumentation. Where more than one code appears in a posting, the finale value is an average of all occurrences.

Reciprocity $(+2,+1,0,-1,-2)$. Yet another important feature of deliberation is reciprocity as described, for instance, by Gutman \& Thompson. This category measures whether other participants are taken into consideration, listened to and included in the process of the debate in a positive or negative way. Again, high values denote high levels of reciprocity and vice versa.

There are three content categories denoting the message content: topic, political versus non-political and meta-debate. 
Topic (categories developed through a grounded approach, reading the debates). This category only applies to dk.politik in order to compare the 2001 analysis of the debate. For the other debates, topics are addressed through a qualitative reading of the debates.

Political versus non-political (political, non-political, political turning non-political, non-political turning political and borderline). These categories illustrate whether a post is political or non-political or whether there are shifts from one to the other. Such a distinction is highly problematic and contested as there are a variety of definitions of what is political, often based on certain normative biases. Here, I subscribe to a classical political science definition, originating with David Easton (1953), that politics is about authoritative values in society. That definition is quite broad since it might encompass all public aspects of society from international politics to childcare. Non-political posts are defined as everything else - for instance, jokes, discussions of hobbies or posts related to the core topic of Cafe Euroinvestor and Trendsales: investments and clothing. Furthermore, some posts are "borderline", not identifiable as political or non-political.

Meta-debate (addressing the debate or not). This is a category that measures whether the post reflects the debate or not. Obvious discussions of the tone, the behavior of the participants or procedures for the debate are coded in this category. The category is only included in the 2011 analysis.

\section{Comparing debates over time: dk.politik in 2001 and 2011}

Dk.politik has been online since the early 1990s and used to be the largest Danish forum for political discussions. Like most Usenet groups, it is initially un-moderated and anarchic. However, there are some guidelines that users are asked to respect: they are to discuss respectfully, follow the debate for a while before posting and identify themselves by name. Likewise, the group has a statement of purpose: it is dedicated to the discussion of certain political topics, whereas some political topics such as immigration, environment and traffic policy are excluded as they have their own dedicated groups within the Usenet hierarchy. Furthermore, commercials, promotion of private websites and the buying and selling off goods are all prohibited. As an un-moderated group, these guidelines are not necessarily adhered to.

My earlier studies based on discussions in 2001 showed that the debate was split in two: a large group of participants discussed respectfully (approximately, half of the postings), whereas the other half of the debate was dominated by a few very eager and not necessarily constructive participants who engaged in endless, often emotionally-loaded discussions about immigration, crime and similar topics. The first part of the analysis addresses whether there has been a deliberative change in the debate of dk.politik over a 10-year span. As mentioned, one might expect changes based on the maturation of the new media, the inclusion of more and more people online (and, thus, also more people debating) and a possible increased awareness of informal rules and appropriate behavior online. 


\section{What is discussed?}

As mentioned, dk.politik is fundamentally an open and anarchic discussion group. In principle, anything can be discussed as long as it is related to politics and political issues. Studies of early Internet debates demonstrated that issues normally covered by the term "symbol politics" - for instance, crime, immigration and identity politics - tended to dominate the debates. Moreover, right-wing debaters and viewpoints were in the majority (Hill \& Hughes, 1998; Davis, 1999). The 2001 study showed that dk.politik followed that trend and was dominated by symbol politics - in particular, long debates about immigration. In fact, many other debates often abruptly changed topics and addressed immigration issues mainly, due to the effort of a small circle of keen (and vociferous) debaters (Linaa Jensen, 2003). It is interesting to see whether such trends have been reduced or strengthened in 2011. Table 2 shows the topics of the debates in 2001 and 2011, respectively. Besides listing percentages for each topic, there are total figures for "symbol politics", "other politics" and "others" (non-political topics).

\begin{tabular}{l|r|r|} 
& 2001 & 2011 \\
\hline Ideology and ethics & 22 & 24 \\
Immigration & 12 & 21 \\
Law and order & 9 & 20 \\
Symbol politics & 42 & 65 \\
\hline Danish Politics & 6 & 4 \\
\hline International Politics & 9 & 0 \\
\hline Economy & 9 & 10 \\
\hline Environemental issues & 5 & 6 \\
\hline Health issues & 5 & 8 \\
\hline Social issues & 4 & 4 \\
\hline Media & 4 & 3 \\
\hline Other politics & 41 & 35 \\
\hline Other & & $\mathbf{6}$ \\
\hline N & 24 & 1465 \\
\hline
\end{tabular}

Table 2. Topics of the debates of dk.politik 2001 and 2011. Percentages of all posts. Note: percentages sum to more than 100 as some posts have more than one topic - altogether 334 topics were coded in 2001 and 1547 in 2011. Sums of "symbol politics" is not equal to sum of sub-topics within the category due to rounding of percentages. 
First and foremost, we see that topics related to symbol politics are even more dominant in 2011 than in 2001. Altogether, two-thirds of all posts address topics related to symbol politics. In 2001, it was only 42 percent. The issue of immigration is discussed in 21 percent of all posts versus 12 percent in 2001. "Law and order" is discussed in 20 percent of all posts versus 9 percent in 2001. Ideological questions are discussed in 24 percent of all posts in 2011 versus 22 percent in 2001. ${ }^{2}$

General (other) political topics are addressed in 41 percent of the posts in 2001 versus 35 percent in 2011, a slight decline. The figures are distributed almost evenly among topics such as Danish politics, economics, environmental issues, health policy, social politics and media. The only real difference between 2001 and 2011 is the almost total absence of posts on international politics in 2011. Even though some of this might be explained by slightly different coding procedures, it is still striking since the development of the codes was also grounded in the material; virtually no discussions of international politics were registered in the explorative reading all of the 2011 debates prior to refining coding categories from 2001.

Another difference is the number of posts categorized as "other". They constitute a compilation of posts in which the discussion is related to topics not strictly political. Examples from the 2011 debate are topics such as "military issues", whereas the 2001 debate contained a large number of posts on historical facts and persons not related to any present political debate. The 2001 debate also consisted of endless discussions of definitions and particular persons or organizations, still not strictly related to politics. As a curiosity, the 2001 debate was also characterized by a small number of participants advocating conspiracy theories - for instance, by claiming that our thoughts and actions are controlled by aliens! The "other" category took up 24 percent of the posts in 2001 versus only 6 percent in 2011. One can argue that the debate is now more "on target", more strictly related to political issues, whether symbol politics or other politics. From a deliberative perspective, this can be regarded as a democratic improvement.

\section{Context}

The context of a debate depends upon who is involved in the discussion. As the present data are based on a content analysis, the only demographic variable, which can be more or less well extracted from the debates, is "gender". In the 2011 analysis, gender is coded based on the revealed identity of the poster, male or female. If the poster does not reveal any identity or if the screen name or e-mail address contains no clue as to gender, it is coded as "not revealed". The 2001 data were based on an explorative survey among participants $(\mathrm{N}=51)$. As they were only a small fraction of those participating, the 2001 data in table 3 must be seen as rather explorative, giving us a hint of the gender composition. 


\begin{tabular}{l|r|r|} 
& 2001 & 2011 \\
\hline Male & 92 & 67 \\
Female & 8 & - \\
Gender not revealed & 51 & 33 \\
N & 51 & 1465 \\
\hline
\end{tabular}

Table 3. The gender of the debates in 2001 and 2011. Percentages.

Note: the 2001 figures are based on data from an explorative survey.

In 2011 they are based on a coding of debates (where gender is often not revealed).

Whereas women made up only a tiny fraction of debaters in 2001 (8 percent), they are virtually non-existent in the 2011 debate ( 0.1 percent, rounded to 0 ). One might argue that women have left Internet debates entirely; but, in order to investigate such claims, we must turn to the comparison of three Internet debates in 2011 later in the article.

The next variable explored is "openness". It is considered a fundamental prerequisite in much deliberative theory that the debaters openly identify themselves, both as a formal procedure and because of the fact that there is a tendency for those remaining anonymous to be more hateful and less deliberative (and vice versa). Table 4 illustrates the openness of participants in 2001 and 2011. As mentioned in the discussion of coding, the "partially open" category denotes those who give a clue as to their identity by name or e-mail address, but their identity cannot be firmly established.

\begin{tabular}{l|r|r|} 
& 2001 & 2011 \\
\hline Open & 57 & 61 \\
Partly open & 16 & 8 \\
Anonymous & 27 & 31 \\
N & 311 & 1465 \\
\hline
\end{tabular}

Table 4. Openness of participants in 2001 and 2011. Percentages.

We see no significant change over the span of 10 years. Slightly more participants openly reveal their identity in 2011, but there are also more who prefer to remain anonymous. What the level of openness more generally means for actions and behavior in the debates is discussed in the last part of this article.

It is a condition in deliberative theory that participants are sincere, respectful and dedicated to a sober debate. Thus, flaming (hateful speech) or intolerance is considered counterproductive to deliberation and democratic dialogue. For both debates, all posts were coded for tone on a scale ranging from +2 to -2 . A positive value denotes respect, soberness and adherence to the debate, and a negative value corresponds to intolerance towards fellow debaters or hateful speech towards third persons. Where different levels of respect or soberness appear within a post, a value was calculated. The average results are figured in table 5. 


\begin{tabular}{l|r|r|} 
& 2001 & 2011 \\
\hline Average & 0.01 & 0.01 \\
$\mathrm{~N}$ & 311 & 1415 \\
\hline
\end{tabular}

Table 5. The level of tone in the debates in 2001 and 2011. Average values.

We see, strikingly, that the average tone in the postings is exactly the same for the two debates: 0.01 , neutral. Those averages hide widely different tones among the debaters. Especially in 2001, a small cohort of debaters was consistently very negative and hateful - mainly, towards each other. In general, it can be concluded that most posts in both years show positive values but that the few very negative posters contribute to a neutral average score. It also seems as if the "chosen few" negative posters annoy those who are interested in a sober debate. Comments on the etiquette of the debates contain numerous complaints about this small group.

\section{Procedures}

We now turn to the deliberative procedures. Here, argumentation is of paramount importance: the best argument "wins" the debate. When coding "argumentation", both the positive and the negative aspects were registered. For the positive aspects, a distinction was made between argumentation validated by facts, information or links (external validation) and argumentation based on reasoning or logic by the participants themselves (internal validation). The coding was based on the formal argumentation; thus, the quality or validity of the argument itself was not examined. Finally, it was also noted when a debater merely asserted statements without any argumentation behind them. The figures for the two debates are provided in table 6.

\begin{tabular}{l|r|r|} 
& 2001 & 2011 \\
\hline External validation (based on facts, sources) & 13 & 4 \\
Internal validation & 23 & 28 \\
Unvalidated statement & 18 & 57 \\
N & 311 & 1465 \\
\hline
\end{tabular}

Table 6. The argumentation in the debates 2001 and 2011. Percentages of all posts.

In 2001, 36 percent of the posts contained argumentation based on internal or external validation; in 2011, the figure is slightly smaller: 32 percent. However, it is characteristic that the fraction of external validation based on sources and information outside the debate had dropped from 13 to 4 percent. This tendency - that the debate has become more closed and self-centered - is supported in the fact that 57 percent of the posts contain unvalidated statements versus 18 percent in 2001. ${ }^{3}$

Another element of deliberation (particularly, for Gutman \& Thompson) is reciprocity, taking the other debaters into consideration. Due to improvements in the research design, the coding in 2011 is slightly more detailed, being divided into five categories rather than 
the three in 2001. Furthermore, only posts demonstrating reciprocity were coded, resulting in $\mathrm{N}=139$ for 2001 and $\mathrm{N}=943$ for 2011.

Thus, in 2001, 45 percent of all posts demonstrated reciprocity. Of those, 10 percent showed that the debater had been convinced or acknowledged the arguments of fellow debaters. 75 percent were reciprocal in the sense that they took other posts into consideration and continued the argumentation. 15 percent contained negative reciprocity in the sense that the poster "flamed" other participants or radicalized his or her views.

In 2011, 64 percent of the posts demonstrate reciprocity, more than in 2001. Only 7 percent show explicit signs of being convinced or an acknowledgement of the viewpoints of others. However, 79 percent are reciprocal, contributing to the flow of the discussion. 14 percent are negatively reciprocal, radicalizing the debate.

From these figures, two things can be concluded; on one hand, the level of reciprocity is higher in 2011 than in 2001. On the other hand, the balance between negative and positive reciprocity remains almost unaltered. The number of those who demonstrate that they have been convinced by or acknowledge the viewpoint of others has even fallen.

In sum, there have been small changes in the debate on dk.politik over a span of ten years. The postings still seem to be divided 50-50 between a small group of "quarrelers" who argue intensively and often "flame" each other and another broader group who try to retain a sober debate. The initial hypothesis that the debate might have changed due to the maturation of the new media and increased skills and awareness among participants is not confirmed. Rather, dk.politik is an isolated forum for people who discuss for the sake of discussion. Many participants are the same in 2011 as in 2001, and they engage in similar discussion, often heavily dominated by "symbol politics".

\section{Comparing different kinds of debates: dk.politik, Cafe Euroinvestor and Trendsales in 2011}

As we have seen only a small development in the level of deliberation and the topics discussed in a debate forum such as dk.politik, it is interesting to compare different kinds of debates with different purposes. In the following, I will compare a debate at dk.politik in April 2011 with those at Cafe Euroinvestor and Trendsales in the same month.

I will look at the same deliberative characteristics of the debates described and discussed above. As a new feature compared to 2001, the role of gender is analyzed. For instance, by selecting a heavily male-dominated forum (Euroinvestor) and one dominated by females (Trendsales), one might expect to discover some gender-based differences in the character and level of deliberation. Furthermore, the 2011 analysis aimed at investigating the borderlines between the political and non-political. It is interesting to compare patterns of discussions among the dedicated political debaters (dk.politik) and the occasionally or accidentally political discussants (Cafe Euroinvestor and Trendsales) - for instance, whether movements can be traced between political and non-political discourses within the postings. 


\section{What is discussed? Cafe Euroinvestor and Trendsales}

As mentioned, Cafe Euroinvestor is a debate forum within the investor website Euroinvestor.dk. Most of the forum is dedicated to topics of investment, economics and finance, but a small sub-forum is dedicated to more general political or societal topics.

The overall topics of the debate are similar to those of dk.politik. ${ }^{4}$ Symbol politics is prevalent in many of the discussions - for instance, immigration and the politics of the Danish right-wing party, Danish People's Party, are eagerly discussed. The debaters demonstrate a fairly strong right-wing bias - probably, characteristic of the majority of participants in an investor forum. The Danish left-wing parties (in April 2011, still in the opposition) are criticized for suggesting unrealistic solutions to economic problems in the country; and, in general, the debaters confirm their viewpoints with like-minded people and show no real willingness to engage in substantial debate. This is illustrated by the typical initial posting in a new debate thread: a participant posts a hyperlink, accompanied by a provocative headline, and the debate takes off. Some people openly admit that they ignore those with whom they disagree.

At Trendsales, the participants (as we shall see, almost exclusively female) discuss issues related to clothing and fashion and, occasionally, political topics. The debates are initially less politicized than at dk.politik and Cafe Euroinvestor. Of the non-political topics, many are related to travel and lifestyle or people asking for general advice about life situations and self-development. Among the political topics, we find many "soft core" political issues such as conditions for handicapped people or traffic safety. Symbol politics, however, also pops up in this debate. Immigration and Muslims are again among the most popular topics.

The debating style is very different compared to the other debates. Many participants deliberately ask for opinions and advice from other people: "What do you think?", "What is your opinion?" Much of the debate is also characterized by phatic communication, discussions for the sake of talking and creating a good mood. It is common among regular visitors to wish each other a nice holiday or to ask whether they had a good weekend.

\section{Gender}

Next, we turn to the issue of gender. Table 7 illustrates the gender composition of the participants in the three debates from 2011.

\begin{tabular}{l|r|r|r|r|} 
& Females & Males & Gender not revealed & N \\
\hline Dk.politik & 0 & 67 & 33 & 1465 \\
Cafe Euroinvestor & 11 & 22 & 67 & 716 \\
Trendsales & 97 & 1 & 2 & 675 \\
All debates & 26 & 40 & 34 & 2856 \\
\hline
\end{tabular}

Table 7. Participants' gender in the three debates. Percentages. 
From the table, it is clear that the initial expectations of the gender distribution are confirmed. Dk.politik and Cafe Euroinvestor are heavily dominated by males. At dk.politik, the few females do not even add up to 1 percent - the exact figure is 0.1 percent. The participants of Trendsales are almost exclusively females. As the identification of gender is based on coding of usernames, a large number of participants - particularly, at Cafe Euroinvestor - remain unidentified. One reason is the dominance of nicknames in the debate, which demonstrates a methodological problem in identifying gender from content analysis only. A survey analysis among participants, for instance, would have given clearer indications of the gender balance. Therefore, in the following, one might be cautious in deriving conclusions about the consequences of the gender difference.

Table 8 addresses the question of openness of the participants. The code "open" means that the participants can be identified by full name or that they reveal their e-mail address. "Anonymous" are those who use either nicknames or dubious e-mail address, perhaps, to avoid spam and other forms of contact. "Partially open" are those who fall in-between. ${ }^{5}$

\begin{tabular}{l|r|r|r|r|} 
& Open & Partly open & Anonymous & N \\
\hline Dk.politik & 61 & 8 & 31 & 1465 \\
Cafe Euroinvestor & 89 & 0 & 11 & 716 \\
Trendsales & 13 & 16 & 70 & 675 \\
All debates & 57 & 8 & 35 & 2856 \\
\hline
\end{tabular}

Table 8. Participants' level of openness in the three debates. Percentages.

We have already seen that about two-thirds of the participants at dk.politik openly reveal their identity. This figure is lower than at Cafe Euroinvestor (89 percent) but much higher than at Trendsales (13 percent). The last figure might be surprising but is due to the fact that many participants at Trendsales use nicknames rather than their real names and that there is no explicit rule that participants must make their e-mail address public to other participants.

Later, I will return to the consequences of gender and openness for the level of debate and deliberation.

The last procedural category is "tone". The category was coded on a scale from +2 to -2 . The average tone for the three debates is shown in the second column of table 9 . It is clear that the tone is most positive and respectful in the debate at Cafe Euroinvestor (0.84) while it is almost neutral in dk.politik (0.01). Such a difference might be due to the gender composition (according to theory), but there could also be other explanations. I will return to these in a following section. 


\section{Procedures}

The next step is to look at two features of deliberation: argumentation and reciprocity. Again, each posting can have an average value between +2 and -2 . Table 9 illustrates the average scores for the three debates, respectively.

\begin{tabular}{l|r|r|r|r|} 
& Tone & Argumentation & Reciprocity & N \\
\hline Dk.politik & 0.01 & -0.56 & 0.33 & 1465 \\
Cafe Euroinvestor & 0.24 & -0.02 & -0.01 & 716 \\
Trendsales & 0.84 & 0.15 & 0.3 & 675 \\
All debates & 0.27 & -0.28 & 0.20 & 2856 \\
\hline
\end{tabular}

Table 9. Tone, argumentation and reciprocity for the three debates. Average values.

The tone is most positive in Trendsales and least in dk.politik. However, all averages are positive. The level of argumentation corresponds to the trend of the tone. The average value of argumentation is positive only for Trendsales, whereas it is lowest for dk.politik, thereby repeating the conclusion from the previous section about the poor quality of argumentation within that debate. For reciprocity, the tendency is a bit reversed: dk.politik and Trendsales have positive scores (around 0.3) while the average score for Cafe Euroinvestor is neutral $(-0.01)$.

The differences might be explained by the various origins and debate cultures within the groups. Dk.politik has always been anarchic and un-moderated, whereas the other debate forums are part of a broader website with a dedicated purpose. Thus, only certain people participate in the debates, whereas dk.politik might become a "garbage can" for those who do not discuss elsewhere. The unofficial rules of Cafe Euroinvestor and Trendsales might also play a role. Finally, gender composition may play a role. Again, this question will be returned to later.

\section{Identifying borderlines - between politics and non-politics}

Another aim of this analysis is to identify and discuss the balance between political and non-political discussions within the groups. ${ }^{6}$ While dk.politik is by nature political, the other debate forums are hosted by websites about investment and clothing - thus, initially, apolitical. However, explorative studies of the discussions demonstrated frequent and rapid shifts from non-political to political topics. The normal everyday discourse of the groups sometimes abruptly turns strictly political - for instance, in the case of Trendsales when economic policy, sustainable clothing production or animal welfare are touched upon. It often happens when participants discuss certain clothing or products that somebody raises concerns about the production process, textile workers' conditions or similar subjects. However, when discussing politics, participants are skilled in staying on topic and, compared to the other debates, they do not frequently change topic in the middle of a thread. 
At Euroinvestor, the shifts are harder to identify. Most often, the topic of the debate is investment or societal conditions related to investment or business affairs. This is true even in the broader debate within the website studied here. However, it seems as if certain debaters want to discuss politics at all times and take any chance to turn debates political. One debate thread (non-political) about the market for summer cabins abruptly turned into a debate about a gang leader who had been granted political asylum in Denmark. The rest of the debate was about "the too generous social benefits in Denmark".

Table 10 shows the political character of the posts for the three debates.

\begin{tabular}{l|r|r|r|r|r|r|} 
& & & Post turns & Post turns & \\
political & a-political & N \\
\hline Dk.politik & 64 & 23 & 10 & 1 & 2 & 1465 \\
Cafe Euroinvestor & 77 & 20 & 1 & 0 & 0 & 716 \\
\hline Trendsales & 20 & 71 & 7 & 0 & 1 & 675 \\
All debates & 57 & 33 & 7 & 1 & 1 & 2856 \\
\hline
\end{tabular}

Table 10. The political character of the posts for the three debates. Percentages.

We find the highest proportion of political content in Cafe Euroinvestor (77 percent) and the lowest in Trendsales (20 percent). One might have expected the highest value to appear in dk.politik, as it is purposely and strictly dedicated to political discussions. The large number of posts about the procedures of the debate and discussions of historical facts and definitions add to this surprising figure. Even though the number of political posts at Trendsales is low, it is still interesting that a fundamentally apolitical forum sometimes turns political. However, the users do not seem to reflect upon these changes. They discuss politics and everyday life in the same way, based on respect and mutual advice. Political discussions are not about fighting but more about small talk. The shifts back and forth take place seamlessly, highlighting expectations that the boundary between everyday talk and political discourse is evaporating. This might also explain why people who are unwilling to engage in dedicated political forums eagerly discuss politics in other contexts.

In other words, some people are eager to discuss politics, as long as this is not the dedicated purpose of the discussion. They are accidentally mobilized. This, of course, has important implications for policymakers and community leaders who want to create online initiatives to facilitate enhanced political involvement in politics and community issues.

Almost no posts shift from non-political content to political or vice versa. Users generally stick to the context and the content. A notable exception was the debate on selling summer cabins that turned into a debate on social policy and the debates on branded clothing that turned into a debate on sustainability and Third World problems. From a methodological point of view, one might argue that such shifts are difficult to observe, and an enhancement and development of the coding procedures might be a task for future research. 


\section{Meta-debate - how the debates maintain themselves}

A last feature of the debates to be analyzed is the extent to which meta-debate appears. Meta-debate is understood as posts discussing the procedures of the debate or the behavior of participants or posts trying to maintain or establish debating norms. At dk.politik, such meta-debates are frequent. In fact, they account for 17 percent of all postings. In the two other debate forums, they are almost absent. At Cafe Euroinvestor, they take up 1 percent of the posts, whereas there are only a couple of posts with meta-debate at Trendsales, not even adding up to 1 percent.

The difference illustrates that dk.politik is the anarchic debate forum in which rules have to be elaborated on the run. Furthermore, the frequent occurrence of hate speech, personal infighting and unfriendly exchanges necessitate constant re-negotiations of appropriate behavior. The other debate forums, especially Trendsales, have more established norms and guidelines. At the latter, the participants seem to agree to maintain a good tone, and the great amount of small talk and mutual recognition help to regulate the debate without having to discuss it explicitly. The norms are tacit, whereas, at dk.politik, they are explicit, fluid and frequently discussed.

\section{Gender and openness - the consequences}

Lastly, I return to the issue of whether the participants' gender and the level of openness, affect the way they discuss things. As mentioned, theoretical expectations are that women are more deliberative than men and that participants who explicitly identify themselves are more deliberative than those who are anonymous. Table 11 illustrates the correlation between gender and openness, and the tone, argumentation and reciprocity for all three debates are combined.

\begin{tabular}{l|r|r|r|} 
& Tone & Argumentation & Reciprocity \\
\hline Gender & $*$ & $*$ & $*$ \\
Female & 0.78 & -0.01 & 0.64 \\
Male & 0.03 & -0.58 & 1.62 \\
Not revealed & 0.16 & -0.15 & 1.71 \\
\hline Openness & & & \\
Anonymous & 0.47 & $*$ & \\
Partly open & 0.37 & -0.08 & 0.28 \\
\hline Open & 0.13 & -0.22 & 0.23 \\
\hline
\end{tabular}

Table 11. The relationship between gender, openness and tone, argumentation and reciprocity for all debates. Average scores.

* signifant correlation between variables on 99 percent level. Gender tested on nominal level, openness on ordinal level. 
The theoretical expectations for the role of gender seem to be partially confirmed. On one hand, females use a more positive tone, and their arguments show a higher level of validation. On the other hand, the average level of reciprocity seems to be higher for the males. In other words, men take the other debaters into consideration to a larger extent than women do.

The findings regarding the role of openness run contrary to initial expectations. The anonymous debaters show a more positive tone, and their arguments have a higher degree of validation. For the correlation between openness and reciprocity, no significant correlation is established, although the anonymous debaters seem to be slightly more reciprocal.

The latter findings are surprising. One might expect that anonymity results in more negative behavior or that those with negative attitudes prefer to remain anonymous, as is known in many Internet debates for political extremists. However, the high level of anonymity at Trendsales, where the debaters generally exhibit a better tone and better arguments, probably contributes to this non-intuitive conclusion. Here, debaters seem to discuss things respectfully and on-topic despite remaining anonymous. As such, the debate comes close to deliberative ideals in which the arguments are of importance rather than the name, job and economic status of the debaters.

\section{Conclusion}

In this article, I have analyzed online debates over time and compared contemporary but very different debate forums.

If one looks solely at dk.politik, one must conclude that little has changed in 10 years. The debates address the same kinds of topics as 10 years ago, and a large number of the participants are the same as in 2001. The conclusion might seem surprising for those who believe that the Internet ought to be a new deliberative forum, channeling the views of the people to the politicians, as Habermas believed was the proper role of the public sphere.

However, the comparative analyses of three debates in 2011 illustrate that online debates are a more diverse and complicated phenomenon than the study of dk.politik suggests - attracting, most often, those who are particularly interested and like-minded. Debates such as those at Cafe Euroinvestor and, particularly, Trendsales seem to play another role. They are places for discussion for people who might not feel attracted to a strictly political forum. While pursuing other interests, they are motivated or mobilized to discuss politics - sometimes, initiated by topics not strictly political. Trendsales is a virtual coffee club, a cozy place for people interested in clothing and fashion who are coincidently drawn into discussing politics. They do not seem to distinguish between political and non-political discussions. They move seamlessly among topics and would probably claim that they are not discussing politics at all.

Similar tendencies can be seen in other online debates and discussion threads at newspaper websites or websites of other mainstream media. There is an interest and a willing- 
ness to discuss political topics as long as the discussions are unofficial and informal. Politics seems to interest people when it is related to everyday life and when it is convenient and safe to discuss. There are a number of interesting future studies to pursue on the factors motivating such citizens to engage more - online and, perhaps, ultimately also offline.

\section{Acknowledgements}

I would like to thank research assistants Ane Kathrine Gammelby and Rikke Ebsen for their huge effort in the coding of the debates.

\section{References}

Albrecht, S. (2006). Whose voice is heard in online deliberation?: A study of participation and representation in political debates on the Internet. Information, Communication \& Society, 9(1), 62-82.

Linaa Jensen, J. (2003). Den digitale demokratiske dialog. Aarhus: Systime Academic.

Linaa Jensen, J. (2006). Den virtuelle kaffestue. Deliberation og demokratisk inklusion i politiske debatter på internettet. Aarhus: Politica.

Barber, B. (1998). A Place for Us: How to Make Society Civil and Democracy Strong. New York: Hill \& Wang. Bessette, J. (1980). Deliberative democracy: The majority principle in republican government. In How Democratic is the Constitution? (pp. 102-116). Washington, D.C., AEI Press.

Bessette, J. (1994). The Mild Voice of Reason: Deliberative Democracy \& American National Government. Chicago: University of Chicago Press.

Butler, J. (1999). Gender Trouble. London: Routledge.

Connolly, W.E. (1983). The Terms of Political Discourse. Princeton: Princeton University Press.

Couldry, N. (2006). Culture and Citizenship - the missing link. European Journal of Cultural Studies, 9(3), 321-339.

Dahlberg, L. (2001). The Internet and democratic discourse: Exploring the prospects of online deliberative forums extending the public sphere. Information, Communication \& Society, 4(4), 615-633.

Davis, R. (1999). The Web of Politics - the Internet's Impact on the American Political System. New York: Oxford University Press.

Easton, D. (1953). The Political System: An Inquiry into the State of Political Science. New York: Knopf.

Elster, J. (ed.) (1998). Deliberative Democracy. Cambridge: Cambridge University Press.

Ess, C. (1996). The political computer: Democracy, CMC, and Habermas. In C. Ess (ed.), Philosophical Perspectives on Computer-Mediated Communication. Albany: SUNY Press.

Gutmann, A. \& D. Thompson (1996). Democracy and Disagreement. Cambridge: Harvard University Press.

Gutmann, A. and D. Thompson (2003). Why Deliberative Democracy? Princeton: Princeton University Press.

Habermas, J. (1989 [1962]). The Structural Transformation of the Public Sphere: An Inquiry into a Category of Bourgeois Society. Cambridge: Polity Press.

Hamilton, A., \& Tolbert, C.J. (2012). Political engagement and the Internet in the 2008 US presidential elections. Digital Media and Political Engagement Worldwide: A Comparative Study, 56.

Herring, S. (1996). Posting in a different voice: Gender and ethics in computer-mediated communication. In C. Ess (ed.), Philosophical Perspectives on Computer-Mediated Communication, (pp. 115-145). New York: SUNY Press. 
Krippendorff, K. (2012). Content Analysis: An Introduction to Its Methodology. London: Sage.

Price, V. (2009). Citizens deliberating online: Theory and some evidence. Online Deliberation: Design,

Research, and Practice, Stanford: CSLI Publications, pp. 37-58.

Yin, R.K. (2003). Case Study Research: Design and Methods. Thousand Oaks: Sage.

Weber, R.P. (1990). Basic Content Analysis. Thousand Oaks: Sage.

Wright, S. (2012). Politics as usual? Revolution, normalization and a new agenda for online deliberation. New Media \& Society", 14(2), 244-261.

van Zoonen, L. (2004). Entertaining the Citizen. New York: Rowman \& Littlefield.

\section{Notes}

1 For subsequent statistical analyses, the category is treated as an ordinal scale variable since the frequency distribution is very $\mathrm{U}$-shaped and, therefore, breaches the conditions for analyses on an interval scale level.

2 Due to slightly different coding procedures, there was a distinction in 2001 between ideology, 13 percent, and ethics, 9 percent.

3 Some of the difference might be explained by a tighter coding procedure in 2011 in which the postings were more rigorously scanned. Thus, some of the mere statements might not have been caught in the 2001 coding. However, the difference is still remarkable.

4 For Cafe Euroinvestor and Trendsales, only qualitative analyses of topics are discussed.

5 It seems strange that the figures for participants not revealing gender are higher than figures for "anonymous" and "partially open". One should expect that those revealing their name or e-mail address might be able to be identified by gender. One part of the explanation is that some e-mail addresses are unclear about gender - for instance, when a family shares an e-mail address. Another explanation might be irregularities in the coding process on this category, but it has not been possible to establish this.

6 The distinction of political and non-political is always a problematic one. Everyday talk and political talk are increasingly interlinked and mixed together, and questions that seem to be non-political may become political and vice versa (van Zoonen, 2004; Couldry, 2006). In this context, I will distinguish political debates as a special case: they are related to societal issues regulated or negotiated by authorities or other formal political institutions, and they are basically about the authoritative distribution of values concerning the society (Easton, 1953). Non-political discussions are, for instance, about holidays, lifestyles, the stock market, etc.

Jakob Linaa Jensen Associate Professor, PhD. Department of Aesthetics and Communication, Media Studies Aarhus University linaa@imv.au.dk 